\title{
INFLUÊNCIA DA INTENÇÃO EMPREENDEDORA DE DISCENTES EM UM INSTITUTO DE ENSINO SUPERIOR
}

DOI: 1014211/Rege33191

Artigo recebido em:02/10/2014

Artigo aprovado em:05/12/2015

Raimundo Eduardo Silveira Fontenele - Universidade Federal do Ceará - UFC ${ }^{1}$ Marcus Vinicius de Oliveira Brasil - Universidade Federal do Cariri - UFCA ${ }^{2}$ Antonia Márcia Rodrigues Sousa- Universidade do Vale do Itajaíl Faculdade Luciano Feijão - UNIVALI/FLF ${ }^{3}$

Resumo: A atenção despertada em todo o mundo para o empreendedorismo aponta os resultados positivos que a formação de ações empreendedoras em vários segmentos da sociedade tem alcançado. Assim, o objetivo geral do estudo é identificar a influência dos antecedentes pessoais, das competências empresarias e do ambiente institucional na intenção empreendedora dos discentes em uma instituição de Ensino Superior. Para isto, buscou-se analisar a intenção empreendedora em uma amostra de 109 discentes em um centro federal de ensino. A metodologia utilizada é a quantitativa foi baseada nas técnicas de Análise Fatorial e na Regressão Logística. A análise dos dados registrou um aumento da intenção para empreender por busca de independência e autoeficácia empreendedora. Por fim, o objetivo foi alcançado em decorrência das análises realizadas e reforçado por meio da validação de $83 \%$ na regressão logística, indicando que é considerado adequado para a realização de predições futuras.

Palavras-chave: Intenção Empreendedora; Ensino Superior; Análise Fatorial; Regressão Logística.

\section{INFLUENCE OF ENTREPRENEURIAL INTENT OF STUDENTS IN AN INSTITUTE OF HIGHER EDUCATION}

\begin{abstract}
The attention aroused worldwide for entrepreneurship indicates the positive results that the formation of entrepreneurial activities in various segments of society has reached. In this line, the objective of this study is to identify the influence of personal background, entrepreneurial skills and the institutional environment on entrepreneurial intention of students in a higher education institution. It was analyzed the entrepreneurial intention in a sample of 109 students in a federal education center. The methodology used is quantitative and it was based on Factor Analysis

\footnotetext{
${ }^{1}$ E-mail: prof.eduardo.fontenele@gmail.com; eduardo@ufc.br

2 Endereço: Rua João Zacarias de Amorim, 184, Limoeiro, Juazeiro do Norte - CE, CEP: 60430-580. E-mail: mvobrasil@gmail.com; marcus.brasil@ufca.edu.br

${ }^{3}$ E-mail: marciauva2@hotmail.com
}

FONTENELE, R. E. S.; BRASIL, M. V. O.; SOUSA, A. M. R. Influência da intenção empreendedora de discentes em um Instituto de Ensino Superior. Revista de 
and Logistic Regression. The data analysis reported an increased intention to undertake for independence status and entrepreneurial self-efficacy search. Finally, the goal was achieved as result of analyzes and reinforced through the validation of $83 \%$ in the logistic regression, indicating that it is considered suitable for the realization of future predictions.

Keywords: Entrepreneurial Intention; Higher Education; Factor Analysis. Logistic Regression.

\section{Introdução}

Estudos mostram que a formação de novas empresas tem uma forte relação com o mundo educacional. As Universidades devem investir no ensino do empreendedorismo como ferramenta para manutenção da empregabilidade de seus alunos, com o intuito de apresentar aos estudantes, aptidões que tornem possível não só a inserção, mas a sobrevivência desses indivíduos no mercado de trabalho (SOUZA, 2001).

Isto vale para o meio acadêmico ao "promover atitudes empreendedoras, a universidade irá contribuir de forma decisiva na ordenação de uma cultura empreendedora, intensificando os esforços no sentido de valorizar e incentivar aqueles que desejam empreender" (CASADO; SILUK; ZAMPIERI, 2012, p. 647).

As Universidades e os centros de Ensino Superior com missão empreendedora, são considerados espaços privilegiados para a disseminação destas visões, em suas estratégias educacionais e pesquisas (LUKMAN; GLAVIC, 2007). No entendimento destes autores, uma sociedade uma forma de alcançar o desenvolvimento sustentável por meio da educação empreendedora e da cidadania ao promover, de forma inclusiva, equitativa e segura, o crescimento econômico, o desenvolvimento social e a proteção ambiental. Assim, estão inclusos: a educação sobre a redução da pobreza, direitos humanos, igualdade de gênero, diversidade cultural, a compreensão internacional e a paz (UNITED NATIONS UNIVERSITY, 2005).

Luz e Cêa (2006) ressaltam que o empreendedorismo vem ganhando cada vez mais espaço na educação brasileira, em função, por exemplo, da publicação de projetos pedagógicos e de publicações centradas da propagação da superioridade empreendedora em relação a outras proposições pedagógicas. A Teoria do Service 
Learning explica essa prática, já que existe um envolvimento dos alunos, docentes e comunidade para a cidadania (SALTMARSH, 1996). Essa é a principal inovação econômica, que se realiza por intermédio de ensino, pesquisa e extensão.

Martens, Freitas e Boissin (2010) verificaram a influência da disciplina de empreendedorismo nas intenções de direcionamento profissional dos estudantes de Ensino Superior a partir da percepção dos que cursaram a disciplina. A pesquisa dos autores teve caráter descritivo, sendo que os dados foram coletados em dois momentos, no primeiro dia de aula e no último. Nesse estudo, ficou evidenciada a contribuição da disciplina na intenção empreendedora, como também sua importância na formação profissional, facilitando e estimulando o comportamento empreendedor do grupo.

Portanto, o desenvolvimento do espírito empreendedor deve ser estimulado na graduação, por ser um espaço laboratorial de conhecimentos teórico e prático, tendo como missão preparar o indivíduo com competências que atendam às exigências do mercado de trabalho. A intenção dos alunos empreendedores está menos voltada para o resultado e mais focada no processo de empreender (ZENG; BU; SU, 2011).

Para Le Boterf (2003), a competência do indivíduo não é um estado, nem mesmo um conhecimento específico, e sim um conjunto composto pela tríade do indivíduo com sua história e socialização, em complemento com sua formação educacional e experiência profissional.

Em muitos casos, os empreendedores possuem uma qualidade distinta que os possibilita enxergar com perspicácia e habilidade de perceber oportunidades que foram negligenciadas, sem necessariamente estarem procurando por isso (KIRZNER, 1973). A intenção pode estar associada a estas oportunidades e, embora de forma imperfeita, pode ser assumida como servindo para prever um determinado comportamento de um indivíduo em relação a fundar a seu próprio negócio (DAVIDSSON, 1995).

Com esta percepção, a questão da presente pesquisa traz uma abordagem à luz do modelo da Teoria do Comportamento Planejado (AJZEN, 1991) e da Teoria da Intenção Empreendedora (SHAPERO; SOKOL, 1982) acerca das variáveis que impulsionam o desenvolvimento de comportamentos e competências 
empreendedoras que podem explicar a intenção empreendedora de discentes. O objetivo geral deste estudo é identificar a influência dos antecedentes pessoais, das competências empresarias e do ambiente institucional na intenção empreendedora dos discentes em uma instituição de Ensino Superior. Os objetivos específicos são estabelecidos de forma a complementar a investigação literária: mapear as influências das características pessoais dos discentes na decisão da criação de uma empresa e analisar a percepção individual dos discentes em relação aos conhecimentos e experiências para o desempenho da função empresarial.

Com o propósito de alcançar tais objetivos, bem como confirmar ou refutar as hipóteses, foram utilizados dois tipos de análise multivariada: (1) Análise Fatorial e (2) Análise de Regressão Logística.

A relevância deste estudo está sedimentada no entendimento de que os discentes visualizam no ambiente universitário um campo de oportunidades que possibilita colocar em prática suas competências e habilidades. Desta forma, os construtos determinados respectivamente pelas Crenças Comportamentais, Crenças Normativas e Crenças de Controle, são fatores que individualmente ou em conjunto influenciam diretamente na intenção empreendedora do indivíduo (AJZEN, 1991).

A estrutura do artigo compreende inicialmente, uma breve fundamentação teórica que discute aspectos relacionados aos construtos norteadores desta pesquisa. Em seguida, expõem-se os procedimentos metodológicos adotados. Posteriormente, é realizada a análise da pesquisa empírica, seguida dos resultados alcançados e das considerações finais sobre o estudo. Por fim, são apresentadas as referências utilizadas.

\section{Modelos de intenção empreendedora}

A literatura psicológica define a intenção como um preditor parcimonioso de comportamento planejado, principalmente se o comportamento é raro, difícil de ser observado, ou envolve tempo para se manifestar (LEITE, 2008).

O uso de modelos de intenção empreendedora decorre do fato de que a opção para iniciar uma atividade empresarial é um comportamento planejado. Os 
indivíduos, em geral, analisam diversos fatores antes de empreender. De acordo com Carland, Boulton e Carland (1984), o empreendedorismo está imbricado ao conceito de competência, pois a busca constante por conhecimentos, habilidades, experiências, capacidade criativa e inovação, são ferramentas que impulsionam o empreendedor a compreender as diferentes facetas do mundo corporativo.

Segundo Leite (2008), os trabalhos que se fundamentam na estrutura teórica da intenção empreendedora utilizam a abordagem de Ajzen (1991) e/ou a proposta de Shapero e Sokol (1982), que buscam entender a preferência ocupacional. Assim, em primeiro lugar, os fatores exógenos influenciam indiretamente o comportamento e as intenções por meio de atitudes. As atitudes, para influenciarem o comportamento, afetam primeiramente a intenção. A intenção, por sua vez, é a variável chave nos modelos que explicam situações reais que exigem uma decisão anterior, isto é, um comportamento planejado. Acrescentando-se orientação individual aos modelos de intenção empresarial seria possível aumentar seu poder explicativo (KUCKERTZ; WAGNER, 2010).

$\mathrm{Na}$ condução desses construtos comportamentais, um dos modelos que apresenta uma interface com as proposições da pesquisa em foco é a Teoria do Comportamento Planejado (TCP), proposta por Ajzen (1991), cuja intenção é compreender no contexto geral as sucessivas modificações que regem as ações empreendidas por meio do comportamento humano. A TCP revela-se como um modelo padrão que exerce expressiva dominância em relação à influência das atitudes sobre o comportamento (AJZEN, 1991).

Krueger e Carsud (1993) foram os primeiros pesquisadores que aplicaram a TCP no campo do Empreendedorismo. Os autores propuseram um modelo adaptado de Shapero e Sokol (1982) à luz da TCP, segundo o qual, a ocorrência da intenção empreendedora do indivíduo decorre de três eventos antecedentes. O primeiro está relacionado ao grau de avaliação pessoal quanto a possíveis reações provocadas pela execução de um comportamento em questão, que pode ser preditor de frágeis ou fortes consequências para o indivíduo. O segundo está interligado nas relações sociais ou crenças normativas, que corresponde a percepção do indivíduo quanto ao julgamento social das suas atitudes. O terceiro vem da convicção do indivíduo em relação ao controle comportamental, que condiz com a capacidade de 
administração de fatos que podem implicar em obstáculo ou aptidão na prática de determinado comportamento (AJZEN; FISBHEIN, 2005).

No processo da intenção empreendedora, esses componentes devem ser somados aos aspectos demográficos, culturais, bem como de trajetórias empresarial e familiar. Esses fatores podem facilitar ou dificultar a ação empreendedora. Para isso, a TCP parte da direção de que as crenças comportamentais, subjetivas e o controle percebido são fatores que influenciam a força da relação entre a intenção de empreender, que são as motivações para agir conforme as crenças e as atitudes.

A Teoria do Comportamento Planejado (TCP) de Ajzen (1991) e a Teoria das Intenções Empreendedora (TIE) de Shapero e Sokol (1982) são destacadas como modelos teóricos dominantes para explicar a intenção empreendedora.

É crescente o número de pesquisas relacionadas à intenção empreendedora e que buscam identificar os construtos que mais influenciem na intenção empreendedora ou motivação empreendedora de estudantes. A seguir, são apresentados de forma sintética os objetivos e os resultados de oito estudos realizados com o propósito mencionado. Cabe salientar que os estudos referidos não são apresentados de forma cronologicamente ordenada.

O trabalho realizado por Morales-Gualdrón, Guitiérrez-Guarcis e Roig-Dóbon (2008) teve por objetivo identificar, por meio da Análise de Equações Estruturais, as motivações empreendedoras de spin-offs acadêmicos, propondo um modelo composto por seis dimensões maiores: pessoal, oportunidade de negócios, conhecimento científico, recursos disponíveis para criar uma nova firma, organização de origem e ambiente social.

O modelo de equações estruturais foi testado em 152 acadêmicos empreendedores espanhóis do curso de empreendedorismo. Os resultados demonstram que a oportunidade empreendedora não faz parte da motivação empreendedora, apesar de muito importante na opinião dos acadêmicos. Os resultados ainda revelaram que o conhecimento científico pode ajudar a resolver problemas na atividade empreendedora desenvolvida pela academia.

Com o propósito de avançar a tese de que o conhecimento por meio da educação formal para o empreendedorismo tem efeitos positivos na intenção empreendedora do indivíduo, mediadas pelas atitudes e normas sociais do 
comportamento empreendedor, os estudos de Roxas, Cayoca-Panizales e Mae de Jesus (2008) apresentam um quadro conceitual guiado pelos principais teóricos do Comportamento Planejado (AJZEN, 1991; KRUEGER; CARSRUD, 1993).

O quadro conceitual proposto naquele estudo é uma tentativa de estabelecer o impacto de programas de educação sobre empreendedorismo nas intenções empreendedoras de estudantes universitários. Para tal, o quadro sugere que o conhecimento empresarial adquirido com estes programas irá influenciar as percepções de um indivíduo sobre sua intenção empreendedora.

Smithikrai (2005) empregou a técnica de regressão múltipla para examinar o potencial empreendedor de estudantes universitários tailandeses, comparando o potencial empreendedor com base em diversas variáveis independentes, procurando saber o poder preditivo da atitude em relação ao empreendedorismo, a norma social e a intenção empreendedora percebida entre os estudantes.

Foram pesquisados 3.154 estudantes em sete universidades estatais, sendo que a pesquisa constatou que não houve diferença significativa no potencial empreendedor entre os estudantes com diferentes gêneros e campos de estudo. No entanto, os resultados apresentaram diferenças significativas no potencial empreendedor entre os alunos envolvidos com negócios e experiências diferentes, renda familiar e com pais de diferentes ocupações. Quanto a intenção empreendedora, houve uma percepção da importância da atitude e da norma social como fatores viabilizadores.

Carvalho e González (2006) investigaram a intenção empreendedora baseada nos estudos de intenção empreendedora de Krueger e Carsud (1993); Davidsson (1995); Autio et al. (1997); Rubio López, Cordón Pozo e Agote Martín (1999). O modelo exploratório-teórico de investigação incluiu os seguintes elementos: antecedentes pessoais, conhecimentos empresariais, motivações empreendedoras, autoeficácia empreendedora e ambiente institucional.

Bayad e Bourguiba (2006), embasados nos estudos de TIE (Gasse, 1982; Stanworth et al., 1989), propuseram uma abordagem que integra as diferentes análises da cultura nacional francesa e consideraram o seu impacto sobre a formação das intenções empreendedoras. 
Com o propósito de identificar as intenções empreendedoras, os autores Lee et al. (2011) aplicaram uma perspectiva multinível pessoa-ambiente e a análise de regressão e correlação, examinando uma amostra de 4.192 profissionais de Tecnologia da Informação (TI) em Cingapura. O objetivo foi o de verificar a influência dos fatores individuais e organizacionais na intenção empreendedora. Os resultados sugeriram que efeitos moderadores em um indivíduo com orientação à inovação fortalecem o ambiente de trabalho nos compostos nas relações satisfação-profissão e autoeficácia, fortalecendo também as intenções empreendedoras.

Giacomin et al. (2010) destinaram-se a analisar se existem diferenças entre alunos de diferentes origens e se a influência da intenção empreendedora por sexo e país do aluno é homogênea. Para a execução da pesquisa, foi selecionada uma amostra de quase 900 estudantes americanos, asiáticos e europeus. Os resultados demonstraram, em primeiro lugar, que dependendo do país, existem diferenças significativas em termos de intenção empreendedora entre homens e mulheres, além da diferença intragrupos.

É preciso salientar ainda o trabalho de Zain, Akram e Ghani (2010). Eles fizeram uma survey com 230 estudantes dos programas da Faculty of Business Management relacionados a cursos de negócios de uma universidade pública da Malásia. O estudo objetivava saber se os estudantes teriam a intenção de abrir uma empresa após o término de seus cursos, examinando traços de personalidade e ambientais, e quais fatores influenciam os alunos a se tornarem empreendedores. Os resultados deste estudo mostram que o traço de personalidade é um determinante importante na intenção empreendedora.

Baseado nos estudos anteriores de Krueger e Carsud (1993); Davidsson (1995); Autio et al. (1997); Rubio López, Cordón Pozo e Agote Martín (1999), é possível compreender que a intenção empreendedora de discentes do Ensino Superior é resultante da prática pedagógica da instituição, mas que outros fatores são conclusivos, tais como: antecedentes pessoais, conhecimentos empresariais, motivações internas para empreender, etc. 


\section{Antecedentes pessoais}

A literatura apresenta argumentações de que é possível perceber a congruência entre determinadas variáveis referentes aos antecedentes pessoais e 0 comportamento empreendedor (STANWORTH et al., 1989).

Dessa forma, Dolabela (1999) afere a existência de três níveis que formam as relações entre aprendizagem e empreendedorismo: o nível primário tem como modelo a família e conhecidos; o secundário tem as redes de ligações e o terciário é por meio de formação continuada e aprimoramento pessoal e intelectual.

O nível primário faz referência à existência de uma fonte de inspiração e aprendizagem para o empreendedor, que é corroborada por Dolabela (1999) ao definir o empreendedor como ser social, produto do meio em que vive. Para emergir no ambiente do empreendedorismo é fundamental seguir pessoas como modelo para repassar as experiências exitosas ou deficitárias (GREATTI et al., 2010).

De acordo com Shapero (1971) variáveis como os traços da personalidade, os elementos de natureza sociodemográfica, idade, sexo, origem, experiência profissional anterior, a formação acadêmica em conjunto com a área cientifica, ano frequentado e estatuto do estudante, formam a intenção empreendedora que influencia na criação de novas empresas.

Em relação ao ambiente familiar e social, estudos apontam que os empreendedores descendentes de grupos empresariais familiares, com altos níveis de rendimento familiar e habilitações acadêmicas dos pais, também podem ser determinantes na intenção empreendedora (HISRISCH, 1990; KETS DE VRIES, 1996).

As relações dessas variáveis convergem para a formação de ambientes propícios no despertar do indivíduo para comportamentos que influenciam diretamente na intenção e no desejo de empreender. 


\section{Conhecimentos empresariais}

Um cenário emergente tem despontado no campo dos conhecimentos empresariais por meio das universidades empreendedoras que vêm possibilitando um apoio sistemático para alunos, professores e pesquisadores com interesse em criar empresa e intenção de explorar comercialmente os resultados das suas pesquisas.

Essa nova modalidade de empreendedorismo são realizadas pelas empresas spin-offs e start-ups acadêmicas. Na literatura especializada, essas empresas são conhecidas por sua transferência de tecnologia entre o ambiente acadêmico e empresarial (SHANE, 2004).

Para a efetivação de um bom desempenho empresarial, é necessário o desenvolvimento de algumas competências que qualificam o indivíduo para as funções empresariais, tais como: a oportunidade que, segundo McClelland (1972), está associada à identificação de novos desafios; a ação proativa; tomar atitudes no momento certo; e aperfeiçoar e expandir os negócios.

O conhecimento conceitual é uma competência fundamental para o sucesso empresarial, pois congrega a capacidade cognitiva, o pensamento analítico, a aprendizagem, a tomada de decisões e a resolução de problemas. Estes aspectos influenciam no desenvolvimento da função empresarial (BIRD, 1995).

Com base nas competências expostas, afere-se que os conhecimentos exigidos para o desempenho da função empresarial extrai a possibilidade de o indivíduo empreender sem a devida intenção.

\section{Motivações empreendedoras}

Muitos comportamentos internos e externos ao ambiente do indivíduo o motivam a criar sua própria empresa. Em geral, os empreendedores não têm como motivação principal a obtenção de riqueza, mas sim a realização pessoal (PINCHOT III, 1989). O desejo de liberdade e independência, em conjunto com a autoconfiança, 
estimula a motivação do empreendedor a trocar a segurança do salário estável pelo risco de um negócio próprio (MCCLELLAND, 1972).

O trabalho de Lili (2011) teve por objetivo revisar a literatura relativa à educação empreendedora e identificar a temática em faculdades chinesas e americanas, sinalizando como medidas importantes para a eficiência do processo: reforçar a formação do professor por meio de treinamento; a formação de equipes empresariais e consultorias; e 0 desenvolvimento da pesquisa sobre 0 empreendedorismo.

Segundo Dolabela (1999) as variáveis habilidade empresarial, o nível de empreendedorismo familiar, a resistência a trabalhar em organizações hierárquicas, a capacidade de conceber ideias, tornando-as criativas para transformá-las em uma oportunidade de negócios, induz o empreendedor à busca de desenvolvimento pessoal. Isto não seria possível se o indivíduo estivesse sujeito à autoridade do emprego tradicional.

A congruência dessas características com o reconhecimento pessoal, autonomia, percepção da instrumentalidade da riqueza e a aprovação social, são fatores que a sociedade e a literatura reconhecem como aspectos motivacionais preponderantes na tomada de decisão para a criação de uma empresa (DAVIDSSON, 1995; VECIANA, 1989).

\section{Autoeficácia empreendedora}

Os empreendedores como atores orientados e dirigidos por metas em geral têm consciência de suas forças e fraquezas. Portanto, eles acreditam em suas capacidades para desempenhar uma determinada tarefa, atribuindo o resultado de suas realizações ao controle e influência de suas próprias ações (BANDURA, 1982; DAVIDSSON, 1995).

A autoeficácia está relacionada ao traço da personalidade e envolve diretamente a motivação pela realização de ações com resultados exitosos, a escolha da carreira compatível com seu ideal, capacidade de tolerância ao risco, a imprevisibilidade, a instabilidade financeira e social (BANDURA, 1982). 
Bandura (1982) argumenta que o nível de motivação, as crenças, os estados afetivos e as ações das pessoas baseiam-se mais no que elas acreditam do que efetivamente nos fatos ocorridos. Com esta argumentação, pode-se aferir que os empreendedores com maior autoeficácia são mais capazes de perseguir e persistir na realização dos seus projetos do que os empreendedores com baixa autoeficácia.

A autoeficácia é um determinante da intenção empreendedora que está relacionado às características da personalidade do indivíduo e implica diretamente na motivação do empreendedor, estimulando a busca pela realização de ações com resultados exitosos (BANDURA, 1982).

A teoria da autoeficácia foi aplicada por alguns autores no estudo da intenção empreendedora. Os modelos de Davidsson (1995) e Autio et al. (1997) apresentam a convicção individual como principal determinante da intenção empreendedora. Este conceito é similar à percepção da autoeficácia, já apresentado em outros trabalhos teóricos (KRUEGER; BRAZAEL, 1994; KRUEGER; CARSRUD, 1993), como também em trabalhos empíricos na área de investigação da intenção e do comportamento empreendedor (KRUEGER; BRAZAEL, 1994; DAVIDSSON, 1995).

\section{Ambiente Institucional}

As mudanças na relação capital-trabalho e a valorização do conhecimento do capital intangível auxiliam a fomentar novas posturas didático-pedagógicas dentro das instituições de Ensino Superior, como forma de contribuir para as novas demandas do mercado, mais especificamente, para o crescimento do empreendedorismo.

O Ensino Superior (ES) está produzindo um número crescente de diplomados e de políticas governamentais em muitos países promovendo pequenos negócios próprios e empregos, apresentando o empreendedorismo como uma opção de carreira viável. (NABI; HOLDEN, 2008, p. 545, tradução nossa). 
A percepção individual acerca da influência do ambiente institucional relacionado com a instituição de Ensino Superior pode demonstrar até que nível este fator vai influenciar as aspirações empresariais dos alunos. Com essa percepção, o ambiente favorável para inovação em uma instituição de Ensino Superior, incentivando a geração de ideias, formação de redes, qualificação de recursos humanos e produtora de conhecimentos, são fatores contributivos para influenciar nas aspirações empresariais dos alunos (AUTIO et al., 1997).

Em um levantamento feito por Li e Liu (2011) na universidade chinesa, denominada Jilin University, demonstrou a importância e o valor da educação para o empreendedorismo e do espírito empreendedor para impulsionar a criação de empregos.

Para complementar e concluir essa ideia, Carvalho (2006) evidencia que quanto mais (menos) elevada for a percepção individual acerca da influência do ambiente da instituição de Ensino Superior, maior (menor) será a probabilidade de o indivíduo ter uma intenção favorável relativamente à alternativa de criar a sua própria empresa.

\section{Questões, dados e objetivos da pesquisa}

O estudo propõe testar a influência de algumas variáveis com a finalidade de explicar as competências que direcionam o indivíduo à intenção empreendedora. Essas variáveis são: conhecimentos empresariais, características pessoais dos empresários, aspirações empreendedoras, pró-atividade empreendedora e estímulo institucional.

Neste caso, o estudo busca analisar a intenção empreendedora no contexto de uma escolha profissional futura, tendo como amostra, os alunos do Ensino Superior, ou seja, é feita uma autoavaliação dos seus juízos sobre a eventualidade de serem donos de suas próprias empresas no futuro.

O procedimento de amostragem foi de caráter não probabilístico, selecionado por conveniência em uma população 506 discentes. Para alcançar os objetivos propostos, optou-se por delimitar a amostra em 109 discentes matriculados 
nos cursos superiores de Mecatrônica Industrial, Engenharia de Alimentos, Saneamento Ambiental e Irrigação e Drenagem. Os discentes são de uma Instituição Federal de Ensino Técnico e Superior do Ceará. Os questionários foram coletados de forma presencial no período de setembro a outubro de 2013.

O instrumento de pesquisa foi elaborado a partir da adaptação da escala desenvolvida por Carvalho (1997). Os dados foram coletados por meio de um questionário composto de 82 questões, subdivididos em etapas: descrição do perfil da amostra, antecedentes pessoais, conhecimentos empresariais, motivação empreendedora, autoeficácia empreendedora, ambiente institucional e intenção empreendedora.

As variáveis independentes foram associadas a uma escala Likert de 7 pontos, seguindo a orientação: (1) discordo totalmente; (2) discordo bastante; (3) discordo um pouco; (4) indiferente; (5) concordo um pouco; (6) concordo bastante; e (7) concordo totalmente. Essas variáveis estão ao lado das afirmações do instrumento.

No caso específico da análise da intenção empreendedora foi utilizada apenas uma questão: "Pretendo vir a criar a minha própria empresa?". Nos casos em que a resposta é afirmativa, foi pedido ao inquirido que indicasse se vai criar a empresa dentro de um ano ou dentro de um a cinco anos, ou então se já é empresário.

\section{Hipóteses da pesquisa}

Uma vez definidos os objetivos do estudo, foram estabelecidas as seguintes hipóteses iniciais de trabalho representativas dos antecedentes pessoais, dos conhecimentos empresariais, das motivações empreendedoras, da autoeficácia empreendedora, do apoio institucional, das variáveis do modelo, da inter-relação entre as variáveis do modelo e da comparação da intenção empreendedora. Deste modo, estabeleceram-se as seguintes hipóteses:

H1: Existe uma relação positiva entre os antecedentes pessoais do aluno e a sua intenção empreendedora; 
H2: Existe uma relação positiva entre a percepção do aluno sobre os seus conhecimentos empresariais e a sua intenção empreendedora;

H3: Existe uma relação positiva entre a percepção do aluno sobre as suas motivações empreendedoras e a sua intenção empreendedora;

H4: Existe uma relação positiva entre a percepção do aluno sobre a autoeficácia empreendedora e a sua intenção de futuramente criar uma empresa;

H5: Existe uma relação positiva entre a percepção do aluno sobre a influência que pode ter a instituição de Ensino Superior por ele frequentada e a sua intenção de futuramente criar uma empresa.

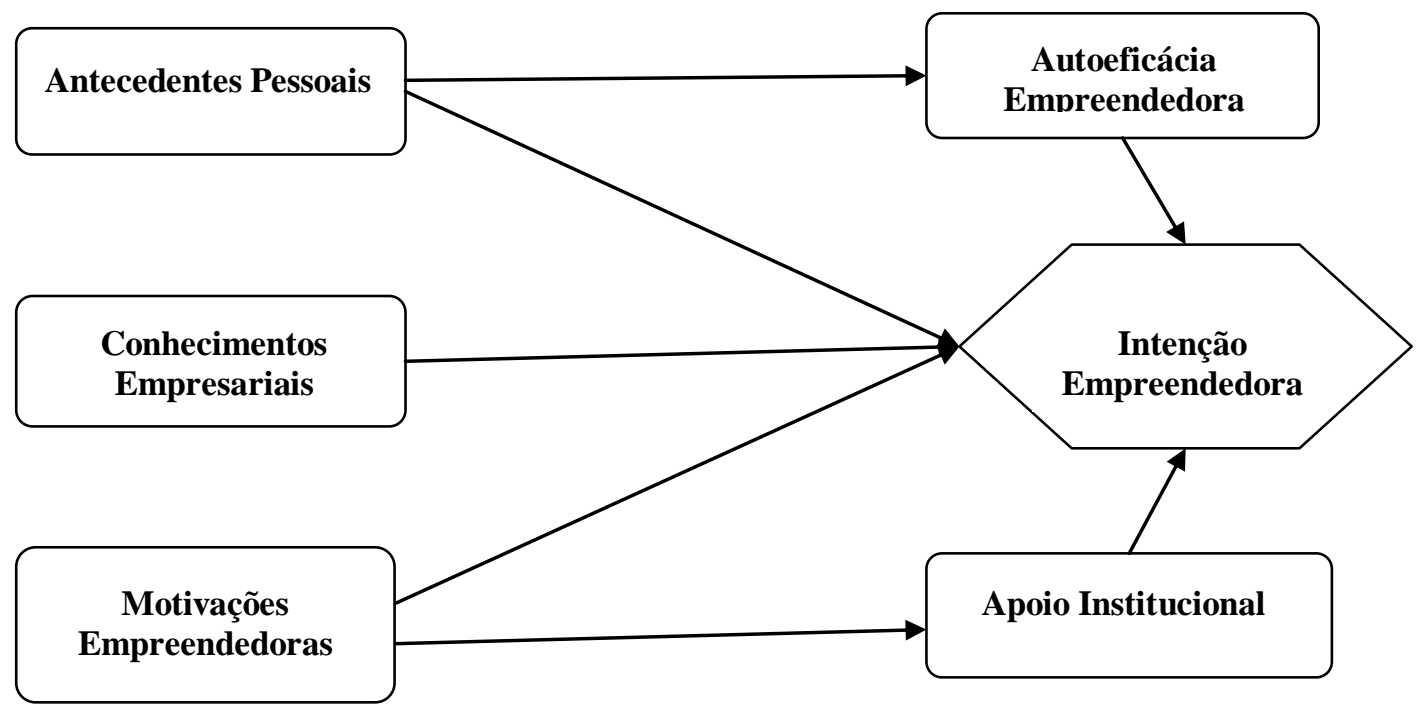

Figura - Modelo Proposto de Identificação dos Determinantes da Intenção Empreendedora

Fonte: Adaptado de Carvalho (1997)

\section{Métodos de análise}

Para o presente estudo, dois tipos de análise foram utilizados: (1) Análise Fatorial e (2) Análise de Regressão Logística.

Desta forma, foi elaborado primeiramente o método de Análise Fatorial para a determinação de fatores que compõem as variáveis apresentadas. Segundo Hair et al. (2009), um fator representa uma combinação linear de variáveis originais. 
Segundo Aaker, Kumar e Day (1998, p. 582), a Análise Fatorial serve para a combinação de variáveis que criam novos fatores.

A Análise Fatorial Exploratória (AFE) consiste em uma técnica multivariada, com o objetivo de determinar fatores ou grupos de variáveis que, por definição, sejam altamente correlacionados e que possam representar dimensões dentro dos dados. Trata-se de uma técnica de interdependência.

O modelo de Análise Fatorial estima os fatores e as variâncias, de modo que as covariâncias ou as correlações previstas estejam o mais próximo possível dos valores observados. Para tal, os métodos de estimação ou extração mais usados são os dos componentes principais e o da máxima verossimilhança.

Neste trabalho, será utilizado o método das componentes principais. No método da máxima verossimilhança, a normalidade é assumida como estabelecida, mas o método dos componentes principais, que é utilizado nesta tese, já não possui essa restrição de que as variáveis envolvidas sigam uma distribuição normal (CORRAR; PAULO; DIAS FILHO, 2009).

Para Hair et al. (2009) a regressão logística tem como principal objetivo determinar a probabilidade de um determinado evento ocorrer, tendo em conta a variável dependente em função das variáveis independentes. Estes mesmos autores elucidam que a finalidade da regressão logística é prever a ocorrência de um evento.

Assim, se a previsão da probabilidade de ocorrência de um evento for superior a 0,50 , então a previsão confirma-se. Por outro lado, se a previsão da probabilidade de ocorrência de um evento for inferior a 0,50, então a previsão não se confirma (CORRAR; PAULO; DIAS FILHO, 2009). No programa SPSS 15.0 existem vários métodos para selecionar as variáveis que entram no modelo. No caso deste trabalho, foi escolhido o método Forward Seleccion (Wald).

\section{Análise dos resultados}

Essa etapa consistiu na aplicação do teste para a verificação da confiabilidade dos constructos. Para isso, utilizou-se o alfa de Cronbach. Para autores como Hair et al. (2009), valores inferiores a 0,60 são tidos como 
questionáveis. O resultado expresso neste teste $(0,933)$ demonstra um excelente grau de ajuste para a aplicação da técnica multivariada Análise Fatorial, sendo ratificado pelo teste Bartlett de Esfericidade ao nível de significância 0,0000 (Tabela 1).

Em uma pesquisa sobre potencial empreendedor envolvendo alunos de graduação no curso de Engenharia da Produção, em uma Universidade Federal, desenvolvida por Minuzzi et al. (2007), obteve um resultado de 0,763. No modelo de Carvalho e Gonzalez (2006), que também trata da intenção empreendedora de discentes, o Alpha de Cronbach, em todos os itens considerados, alcançaram índices superiores a 0,60.

Tabela 1 - Teste Alfa de Cronbach

\begin{tabular}{c|c|c}
\hline $\begin{array}{l}\text { Cronbach's } \\
\text { Alpha }\end{array}$ & $\begin{array}{l}\text { Cronchbach's Alpha Based } \\
\text { on Standardized Items }\end{array}$ & No. Items \\
\hline 0,933 & 0,940 & 82 \\
\hline
\end{tabular}

Fonte: Os autores (2015).

Tabela 2 - Teste KMO e Barlett

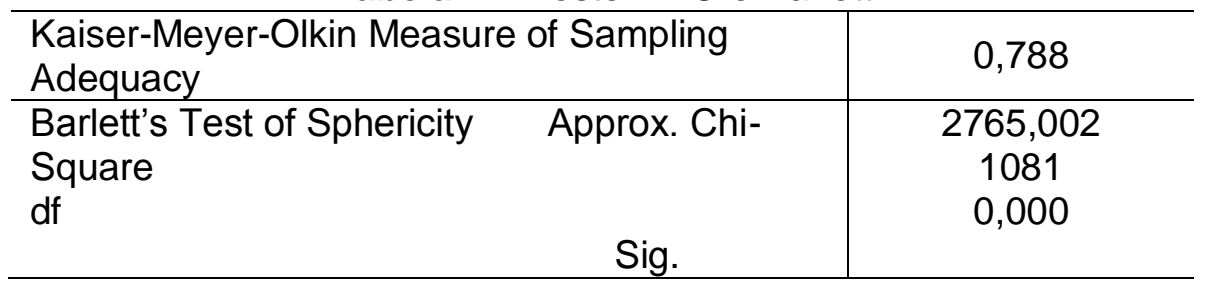

Fonte: Os autores (2015).

Utilizando-se da Análise de Componentes Principais, foi observado que $71,9 \%$ do total da variância pode ser explicada por 13 fatores. O mesmo resultado foi obtido ao se fazer a análise dos autovalores maiores que 1. Estes resultados podem ser observados na Tabela 3.

Os fatores extraídos por meio da rotação Varimax foram submetidos ao teste de confiabilidade Alfa de Cronbach, onde o valor mínimo é de 0,6 por se tratar de uma pesquisa exploratória. As variáveis que foram excluídas da análise passaram por uma série de testes para verificar se era possível criar agrupamentos que pudessem resultar em outros fatores, que isolados, comporiam o modelo de regressão logística. 
Tabela 3 - Autovalores e porcentagem da variância explicada

\begin{tabular}{c|c|c|c}
\multicolumn{2}{l|}{$\begin{array}{c}\text { Component } \\
\text { es }\end{array}$} & \multicolumn{3}{|c}{ Autovalores Iniciais } \\
\cline { 2 - 4 } & Total & $\begin{array}{c}\% \text { da } \\
\text { Variância }\end{array}$ & $\begin{array}{c}\% \text { da Var. } \\
\text { Acumulada }\end{array}$ \\
\hline 1 & 11,601 & 25,220 & 25,220 \\
2 & 4,612 & 10,025 & 35,245 \\
3 & 2,391 & 5,197 & 40,442 \\
4 & 2,063 & 4,486 & 44,927 \\
5 & 1,842 & 4,004 & 48,931 \\
6 & 1,654 & 3,597 & 52,527 \\
7 & 1,562 & 3,396 & 55,923 \\
8 & 1,403 & 3,050 & 58,973 \\
9 & 1,381 & 3,002 & 61,975 \\
10 & 1,273 & 2,767 & 64,742 \\
11 & 1,131 & 2,459 & 67,201 \\
12 & 1,097 & 2,384 & 69,585 \\
13 & 1,046 & 2,275 & 71,860 \\
\hline
\end{tabular}

Fonte: Os autores (2015).

Utilizando-se o método de Componentes Principais, a Tabela 4 mostra as variáveis que formam cada fator, com suas respectivas cargas. 
Tabela 4 - Composição dos Fatores com respectivas cargas

\begin{tabular}{|c|c|c|c|}
\hline $\begin{array}{l}\text { FATO } \\
\text { R }\end{array}$ & VARIÁVEIS & $\begin{array}{c}\text { CARG } \\
\text { A }\end{array}$ & $\begin{array}{c}\text { ALFA DE } \\
\text { CRONBAC } \\
\text { H }\end{array}$ \\
\hline 1 & $\begin{array}{l}\text { Organizar_Trabalho_Função_Objetivos (OTFO) } \\
\text { Estruturar_Empresa (EE) } \\
\text { Analisar_Resultados (AR) } \\
\text { Tomar_Decisões_Estratégicas (TDE) } \\
\text { Implementar_Novas_Áreas_Negócios (INAN) } \\
\text { Não_Deixar_Empresa_Entrar_Declínio (NDEED) } \\
\text { Controlar_Funcionamento (CF) }\end{array}$ & $\begin{array}{l}0,649 \\
0,620 \\
0,675 \\
0,694 \\
0,658 \\
0,779 \\
0,672\end{array}$ & 0,878 \\
\hline 2 & $\begin{array}{l}\text { Ganhar_Prestígio_Sociedade (GPS) } \\
\text { Realizar_Algo_Ser_Reconhecido_Isso (RASRI) } \\
\text { Ter_Mais_Influência_Sociedade (TMIS) } \\
\text { Ser_Mais_Respeitado_Amigos_Colegas (SMRAC) }\end{array}$ & $\begin{array}{l}0,767 \\
0,808 \\
0,868 \\
0,770\end{array}$ & 0,876 \\
\hline 3 & $\begin{array}{l}\text { Relaciono_Facilmente (RF) } \\
\text { Negociar (N) } \\
\text { Interagir_Outros (IO) } \\
\text { Estabelecer_Contatos (EC) } \\
\text { Entender_Necessidades (EN) } \\
\text { Comunicar_Corretamente (CC) }\end{array}$ & $\begin{array}{l}0,639 \\
0,533 \\
0,729 \\
0,612 \\
0,634 \\
0,750\end{array}$ & 0,834 \\
\hline 4 & $\begin{array}{l}\text { Pra_Mim_E_Mais_Fácil_Carreira_Empresário (PMM) } \\
\text { Se_Eu_Quiser_Vou_Ser_Muito_Bem_Sucedido_Empresá } \\
\text { rio(SEQ) } \\
\text { Ser_Empresário_Possibilita_Maior_Independência } \\
\text { (SEPMI) } \\
\text { Ser_Empresário_Possibilita_Melhor_Controle_Tempo } \\
\text { (SEP) } \\
\text { Vou_Ser_Empresário_Sucesso (VSES) }\end{array}$ & $\begin{array}{l}0,574 \\
0,828 \\
0,628 \\
0,647 \\
0,612\end{array}$ & 0,801 \\
\hline 5 & $\begin{array}{l}\text { Identifica_Necessidades (IN) } \\
\text { Identifica_Oportunidades (IO) }\end{array}$ & $\begin{array}{l}0,778 \\
0,667\end{array}$ & 0,635 \\
\hline 6 & $\begin{array}{l}\text { Liderar (L) } \\
\text { Gerir_Pessoal (GP) } \\
\text { Delegar_Tarefas (DT) }\end{array}$ & $\begin{array}{l}0,603 \\
0,666 \\
0,734\end{array}$ & 0,727 \\
\hline 7 & $\begin{array}{l}\text { Decidir_Conforme_Plano_Estratégico (DCPE) } \\
\text { Ter_Mais_Flexibilidade_Vida_Privada (TMFVP) }\end{array}$ & $\begin{array}{l}0,524 \\
0,703\end{array}$ & 0,600 \\
\hline 8 & $\begin{array}{l}\text { Coordenar_Tarefas }(\mathrm{CT}) \\
\text { Elaborar_Plano_Estratégico (EPE) }\end{array}$ & $\begin{array}{l}0,633 \\
0,629 \\
\end{array}$ & 0,641 \\
\hline 9 & $\begin{array}{l}\text { Fugir_Desemprego (FD) } \\
\text { Ter_Mais_Segurança_Futuro (TMSF) }\end{array}$ & $\begin{array}{l}0,798 \\
0,509\end{array}$ & 0,771 \\
\hline 10 & Explora_Ideias (EI) & 0,586 & - \\
\hline 11 & Implementar_Negócio_Inovador (INI) & 0,794 & - \\
\hline 12 & Ter_Mais_Rendimentos(TM) & 0,812 & - \\
\hline 13 & $\begin{array}{l}\text { Hipóteses_de_Falência_Empresa_Serão_Baixas } \\
\text { (HFESB) }\end{array}$ & 0,725 & - \\
\hline
\end{tabular}

Fonte: Os autores (2015).

Com os dados obtidos, desenvolveu-se a construção dos modelos de regressão logística, utilizando-se o software estatístico SPSS. Em cada simulação, 
foi realizado o teste de qualidade de ajuste de Hosmer e Lemeshow, que indicou a possibilidade de realização da regressão logística em cada uma delas.

A aplicação da técnica estatística da regressão logística, com a finalidade de analisar a existência de uma relação entre os determinantes do modelo apresentado e a sua intenção para a criação de uma empresa, permitiu confirmar só algumas das hipóteses formuladas.

Apresenta-se na sequência, o modelo que se mostrou com resultados mais adequados e maior força de predição. Outro fato que justificou a escolha deste modelo é por ele ter englobado todos os cinco constructos investigados na pesquisa.

A partir dos fatores resultantes da Análise Fatorial (Tabela 4), a simulação escolhida utilizou como variáveis independentes os constructos referentes a: Planejamento (Fator 1), Necessidade de Realização (Fator 2), Rede de Relacionamento (Fator 3), Necessidade de Independência (Fator 4), Identificação de Oportunidades (Fator 5), Liderança (Fator 6), Estratégia (Fator 7), Coordenação (Fator 8), Necessidade de Segurança (Fator 9), Visão (Fator 10), Inovação (Fator 11), Motivações Financeiras (Fator 12) e Autoeficácia empreendedora (Fator 13).

Seguindo o método Forward Selection (Wald) para selecionar as variáveis explicativas do modelo obteve-se o seguinte odds ratio (no passo 2):

$$
\frac{P R O B_{(\text {Ter Intenção empreendedora })}}{P R O B_{(\text {Não ter Intenção empreendedora })}}=e^{1,872+0,865_{\text {Independência }}+0,672_{\text {Estratégia }}}
$$

Um valor do odds ratio é calculado para cada variável explicativa do modelo logístico, o que demonstra a variação na medida em que o valor da variável explicativa é acrescido em uma unidade. Assim, uma variação positiva de uma unidade nas variáveis Fator: 4 (Necessidade de Independência) e Fator 7: (Estratégia) apresenta um elevado impacto positivo na probabilidade de um aluno ter intenção empreendedora, ou seja, quanto maior for o valor dessas variáveis, maior é a probabilidade do aluno ter intenção empreendedora e logo menor é a probabilidade de não a ter.

Contrariamente as pesquisas anteriores (SCOTT; TWOMEY, 1988; MARTENS; FREITAS; BOISSIN, 2010), o potencial empreendedor dos estudantes 
do Instituto Federal de Ensino não evidenciou estar relacionado com as suas atividades extracurriculares e experiências profissionais.

Verificou-se ainda que o contexto familiar (existência de familiares empreendedores) dos estudantes não parece influir no seu desejo de criar um negócio no final dos seus estudos. Essas observações não coincidem com os resultados apresentados na literatura, que evidenciam existir uma relação positiva entre as famílias com um exemplo empreendedor e o potencial empreendedor dos estudantes (BROCKHAUS, 1982; SCOTT; TWOMEY 1988; BRUSH, 1992; COOPER; DUNKELBERG, 1986; KRUEGER; BRAZEAL, 1994).

Entretanto, a hipótese que estabelece uma relação entre a percepção do aluno em relação à necessidade de independência e a sua intenção de futuramente criar uma empresa se confirma. Este resultado é similar ao obtido em trabalhos que estudam as motivações empresariais (COLLINS; MOORE, 1964; SHAPERO, 1971; VECIANA, 1989; SCOTT; TWOMEY, 1988).

A hipótese que pretendia estabelecer uma relação entre a percepção do aluno sobre os seus conhecimentos empresariais foi parcialmente atendida com a obtenção de uma relação positiva dos conhecimentos de estratégia e a sua intenção empreendedora. Este resultado está de acordo com os trabalhos sobre os conhecimentos empresariais de McClelland (1987), Mitton (1989), Snell e Lau (1994), Man (2001), em que postulam ser fundamental para um bom desempenho da função de empresário que este tenha conhecimentos para elaborar e implantar um plano estratégico para a empresa.

A Tabela 5 demonstra que as variáveis explicativas apresentaram significância (Sig.) inferior a 0,1\%, ou seja, pode-se concluir com um nível de confiança de 99,9\% que na amostra dos alunos do Instituto de Ensino Superior, existe uma relação entre estas variáveis e a probabilidade de o aluno ter ou não intenção empreendedora. 
Tabela 5 - Variáveis do Modelo

\begin{tabular}{c|c|c|c|c|c}
\hline Variável & $\begin{array}{c}\text { Coeficien } \\
\text { te } \\
\text { B }\end{array}$ & $\begin{array}{c}\text { Erro } \\
\text { standar } \\
\mathbf{d} \\
\text { S.E. }\end{array}$ & $\begin{array}{c}\text { Estatísti } \\
\text { ca } \\
\text { Wald }\end{array}$ & $\begin{array}{c}\text { Nível de } \\
\text { Significânc } \\
\text { ia }\end{array}$ & $\begin{array}{c}\text { Odds } \\
\text { ration } \\
\text { Exp (B) }\end{array}$ \\
\hline Indep. & 0,865 & 0,271 & 10,225 & 0,001 & 2,375 \\
Estrat. & 0,672 & 0,288 & 5,459 & 0,019 & 1,958 \\
$\begin{array}{c}\text { Constan } \\
\text { t }\end{array}$ & 1,872 & 0,314 & 35,510 & 0,000 & 6,499 \\
\hline
\end{tabular}

Fonte: Os autores (2015).

No que se refere à avaliação da qualidade do ajustamento, o modelo a Tabela 6 apresenta os valores das quatro medidas: - 2 log likelihood, Cox \& Snell, Nagelkerke e Teste de Hosmer \& Lemeshow. O valor da medida - 2 log likelihood é igual a 83,482. Quanto aos coeficientes de determinação de Cox \& Snell e de Nagelkerke, estes indicam, respectivamente, que as duas variáveis independentes selecionadas do modelo logístico estimado explicam $14,7 \%$ e $24,4 \%$ da variância da variável dependente, o que pode ser considerado um valor razoável da qualidade de ajustamento. O valor de Hosmer \& Lemeshow apresentou uma distribuição Quiquadrado de 12,007 e um nível de significância de 0,151, o que indica que não há diferenças significativas entre as frequências previstas e as observadas.

Tabela 6 - Ajuste do Modelo

\begin{tabular}{|c|c|c|c|c|c|}
\hline $\begin{array}{l}-2 \text { Log } \\
\text { likelihood }\end{array}$ & $\begin{array}{c}\text { Cox \& } \\
\text { Snell } \\
R^{2}\end{array}$ & $\begin{array}{l}\text { Nagelkerk } \\
\quad e R^{2}\end{array}$ & \multicolumn{3}{|c|}{$\begin{array}{c}\text { Teste de Hosmer \& } \\
\text { Lemeshow }\end{array}$} \\
\hline 83,482 & 0,147 & 0,244 & 12,007 & 8 & 0,151 \\
\hline
\end{tabular}

Fonte: Os autores (2015)

Este resultado é um pouco diferente do obtido em outros estudos. No modelo de Carvalho e Gonzalez (2006) o R2 obtido nos sete modelos testados, tendo em conta a medida de Nagelkerke, varia entre o valor mínimo de 0,024 e o valor máximo de 0,24.

A Tabela 7 apresenta a capacidade de classificação correta dos eventos do modelo. Assim, o percentual de acerto dos alunos que não tem intenção empreendedora é de $26,3 \%(=5 /(5+14))$ e os que estão dispostos a empreender seria de $97,8 \%(=102 /(102+7))$. O modelo logístico apresenta um acerto global de 
$85,3 \%(=(5+88) /(5+14+2+88))$, o que atesta uma excelente capacidade de previsão do modelo.

Estes resultados são diferentes do estudo de Carvalho e Gonzalez (2006), cujo modelo logístico não conseguiu classificar corretamente $36,9 \%$ dos alunos sem intenção empreendedora e 25,3\% com intenção empreendedora, classificando corretamente $69,3 \%$ do total da amostra.

Tabela 7 - Classificação da Intenção Empreendedora dos Alunos no Modelo Logístico Obtido

\begin{tabular}{cc|c|c|c|c}
\hline \multirow{2}{*}{ Grupo Observado } & \multicolumn{4}{c}{ Grupo Predito } \\
\cline { 2 - 4 } & \multicolumn{2}{|c|}{ Intenção } & Total & $\begin{array}{c}\text { \% do } \\
\text { acerto }\end{array}$ \\
\cline { 2 - 3 } & Não & Sim & & \\
\hline \multirow{2}{*}{ Intenção Simo } & 5 & 14 & 19 & 26,3 \\
\multicolumn{2}{c|}{ Total } & 2 & 88 & 90 & 97,8 \\
& 7 & 102 & 109 & 85,3 \\
\hline
\end{tabular}

Fonte: Os autores (2015).

Considerações finais

Pela análise realizada, ficou evidenciado que a primeira hipótese de pesquisa, relacionada aos aspectos socioeconômicos (faixa etária, experiência profissional, gênero e realização de cursos), como aspectos que influenciam mais fortemente na intenção empreendedora, não é confirmada, bem como o ambiente institucional. Este resultado é diferente do obtido em outros estudos que mostraram existir uma correlação positiva entre a faixa etária e a decisão de criar uma empresa (BROCKHAUS, 1982; REYNOLDS, 1995; SHAPERO, 1971; PETROF, 1980; DAVIDSSON, 1995).

Este resultado é também diferente dos obtidos por Gibb (1993) e Cooper e Dunkelberg (1986), que concluíram que a experiência profissional como um fator muito importante na intenção para a criação de novas empresas.

O estudo também não verificou uma relação significativa entre o nível de rendimento dos pais do aluno e a sua intenção empreendedora. Este resultado é 
diferente do obtido em outros estudos (REYNOLDS, 1991; COLLINS; MOORE, 1964; VECIANA, 1989; CARVALHO, 1997).

A Tabela 5 confirma parcialmente as hipóteses 1 e 2 da pesquisa, pois as variáveis com resultados mais adequados e maior força de predição foram Necessidade de Independência e Estratégia. Este resultado vem corroborar os trabalhos que estudam as motivações empresariais (COLLINS; MOORE, 1964; SHAPERO, 1971), principalmente no que se refere à percepção do aluno acerca do desejo de autonomia estar relacionada com a sua intenção de criar uma empresa.

Por fim, o objetivo geral de identificar a influência dos antecedentes pessoais e das competências empresariais na intenção empreendedora dos discentes em uma instituição de Ensino Superior foi alcançado, sendo considerado adequado para a realização de predições futuras.

Para estudos futuros, recomenda-se que apresente maior abrangência, sendo realizado em outras instituições de Ensino Superior e com tamanhos de amostras diferentes. É importante também aumentar a variedade de cursos a serem pesquisados, não se limitando somente a um curso. De igual forma, é preciso verificar se tais vertentes de pesquisas chegariam às mesmas conclusões.

Esse levantamento poderia ser ampliado por meio do desenvolvimento de um estudo comparativo quanto à intenção empreendedora entre estudantes de regiões e/ou Estados distintos como, por exemplo, Piauí, Ceará e Maranhão.

Outra recomendação é quanto ao caráter subjetivo observado quando da aplicação dos questionários, o que possibilitaria, somado ao caráter quantitativo do estudo, o desenvolvimento de uma teoria mais consistente sobre o tema. No entanto, não foram esgotadas todas as possíveis análises de tratamento dos dados, como seria o caso, por exemplo, de aplicar a técnica estatística das equações estruturais (path analysis).

Fica também a sugestão em sistematizar a realização de pesquisas com o mesmo objetivo periodicamente, como alternativa de verificação da evolução da influência de tais aspectos socioeconômicos e comportamentais na intenção empreendedora. 


\section{Agradecimentos}

Agradecemos à Coordenação de Aperfeiçoamento de Pessoal de Nível Superior (CAPES) pelo apoio da execução deste trabalho.

\section{Referências:}

AAKER, D.; KUMAR, V.; DAY, G. Marketing research. 6. ed. New York: John Wiley \& Sons Inc., 1998.

AJZEN, I. Theory of planned behavior. Organizational Behavior and Human Decision Process, v. 50, p. $179-211,1991$.

AJZEN, I.; FISHBEIN, M. The influence of attitudes on behavior. In: ALBARRACÍN, D.; JOHNSON, B. T.; ZANNA, M. P. (Eds.). The handbook of attitudes. Mahwah, NJ: Erlbaum, 2005. p. 173 - 221.

AUTIO, E. et al. Entrepreneurial intent among students. Testing an intent model in Asia, Scandinavia and USA. In.: Frontiers of Entrepreneurship Research, 1997, Babson Park. Anais...College Entrepreneurship Research Conference, 1997.

BANDURA, A. Self-Efficacy mechanism in human agency. American Psychologist, v. 37, n. 2, p. $122-147,1982$.

BAYAD, M; BOURGUIBA, M. De l'universalisme à la contingence culturelle: réflexion sur l'intention entrepreneuriale. In.: $8^{\mathrm{e}}$ CONGRÉS INTERNATIONAL FRANCOPHONE EM ENTREPRENEURIAT ET PME, 2006, Fribourg. Anais... Fribourg, 2006.

BIRD, B. Towards a theory of entrepreneurial competency. Advances in entrepreneurship, Firm Emergence and Growth, v. 2, n.1, p. 51 - 72, 1995.

BROCKHAUS, R. H. The Psychology of the Entrepreneur. Encyclopedia of Entrepreneurship, Englewood Cliffs, NJ: Prentice-Hall, 1982, p. $39-71$.

BRUSH, C. Research on women business owner: Past trends, new perspective and future directions. Entrepreneurship Theory and Practice, v. 16, n. 4, p. 5 - 30, 1992.

FONTENELE, R. E. S.; BRASIL, M. V. O.; SOUSA, A. M. R. Influência da intenção empreendedora de discentes em um Instituto de Ensino Superior. Revista de 
CARLAND, J. W.; HOY, F.; BOULTON, W. R.; CARLAND, J. A. Differentiating entrepreneurs from small business owners: A conceptualization. The Academy of Management Review, v. 9, n. 2, p. $354-359,1984$.

CARVALHO, P. M. R. Características e motivações dos empresários: o caso dos fundadores de pequenos negócios na cidade da Guarda. Anais Universitários, Série de Ciências Sociais e Humanas, v. 8, p. 107 - 136, 1997.

CARVALHO, P. M. R. de.; GONZÁLEZ, L. Modelo explicativo sobre a intenção empreendedora. Comportamento Organizacional e Gestão, v. 12, n. 1, p. 43 - 65, 2006.

CASADO, F. L.; SILUK, J. C. M.; ZAMPIERI, N. L. V. Universidade empreendedora e desenvolvimento regional sustentável: uma proposta de um modelo. Rev. Adm. UFSM, v. 5, p. 633 - 650, 2012.

COOLINS, O. F.; MOORE, D. G. The enterprising man. East Lansing: Michigan State University Press, 1964.

COOPER, A. C; DUNKELBERG, W. C. Entrepreneurship and Paths to Business Ownership. Strategic Management Journal, v. 7, n. 1, p. 53-68,1986.

CORRAR, L. J.; PAULO, E.; DIAS FILHO, J. M. Análise multivariada. São Paulo: Atlas, 2009.

DAVIDSSON, P. Determinants of entrepreneurial intentions. In.: RENT XI WORKSHOP, 1995, Piacenza. Anais..., Piacenza, 1995.

DOLABELA, F. Segredo de Luiza. São Paulo: Cultura, 1999.

GASSE, Y. Elaborations on the psychology of the entrepreneur. Encyclopedia of Entrepreneurship, Englewood Cliffs, NJ: Prentice-Hall, 1982, p. 57 - 71.

GIACOMIN, O. et al. Impact du sexe et de l'auto-efficacite entrepreneuriale sur l'intention entrepreneuriale des etudiants: une comparaison internationale. In.: 10ĖME CONGRÈS INTERNATIONALE FRANCOPHONE EN ENTREPRENEURIAT ET PME (CIFEPME), 2010, Bordeaux. Anais... Bordeaux, 2010.

GIBB, A. The enterprise culture and education. Understanding enterprise education and its links with small business. Entrepreneurship and wider educational goals. International Small Business, v. 3, n. 11, 1993.

FONTENELE, R. E. S.; BRASIL, M. V. O.; SOUSA, A. M. R. Influência da intenção empreendedora de discentes em um Instituto de Ensino Superior. Revista de 
GREATTI, L.; GRALIK, E.; VIEIRA. F. G. D.; SELA, V. M. Aprendizagem em empreendedorismo dos acadêmicos do curso de administração de uma Universidade Estadual do Sul do Brasil. In.: XXXIV ENCONTRO NACIONAL DOS PROGRAMAS DE PÓSGRADUAÇÃO EM ADMINISTRAÇÃO, 34, 2010, Rio de Janeiro. Anais... Rio de Janeiro: ANPAD, 2010. 1 CD.

HAIR, J. F. et al. Análise Multivariada de dados. 6. ed. Porto Alegre: Bookman, 2009.

HISRISH, R.D. Entrepreneurship/Intrapreneurship. American Psychologist, v. 45, n. 2, p. $209-222,1990$.

KETS DE VRIES, M. F. R. The anatomy of entrepreneur: Clinical observations. Human Relations, v. 49, n. 7, p. $853-883,1996$.

KIRZNER, I. Competition and Entrepreneurship. Chicago: University of Chicago Press, 1973.

KRUEGER, N.; CARSUD, A. Entrepreneurship intentions: applying the theory of planned behaviour. Entrepreneurship \& Regional Development, v. 5, p. $316-323$, 1993.

KRUEGER, N.F.; BRAZEAL, D.V. Entrepreneurial Potential and Potential Entrepreneurs. Entrepreneurship Theory and Practice, v.18, n. 3, p. $91-104$, 1994.

KUCKERTZ, A.; WAGNER, M. The influence of sustainability orientation on entrepreneurial intentions- Investigating the role of business experience. Journal of Business Venturing, n. 25, p. 524 - 539, 2010.

LE BOTERF, G. Desenvolvendo a Competência dos Profissionais. Porto Alegre: Artmed Editora, 2003.

LEE, L. et al. Entrepreneurial intentions: The influence of organizational and individual factors. Journal of Business Venturing, v. 26, n. 1, p. $124-136,2011$.

LEITE, S. C. F. Capital empresarial: um estudo de caso para o agronegócio. Tese (Doutorado em Economia) - Escola Superior de Agricultura Luiz de Queiroz, Universidade de São Paulo, Piracicaba. 2008. 
LI, Z.; LIU, Y. Entrepreneurship education and employment performance: An empirical study in Chinese university. Journal of Chinese Entrepreneurship, v. 3, n. 3, p. $195-203,2011$.

LILI, Z. Comparative study of China and USA's colleges entrepreneurship education from an international perspective. Journal of Chinese Entrepreneurship, v. 3, n. 3, p. $185-194,2011$.

LUKMAN, R.; GLAVIC, P. What are the key elements of a sustainable university? Clean Tech. Environ. Policy, n. 9, p. 103 - 114, 2007.

LUZ, A. S. da; CÊA, G. S. dos S. Reflexões sobre a Ideia do Empreendedorismo. Educere et Educare, v. 1, n. 1, p. $83-87,2006$.

MAN, T. W. Y. Entrepreneurial competencies and the performance of small and medium enterprises in the Hong Kong services sector. $346 \mathrm{f}$. Tese (Doutorado em Filosofia) - Departamento de Gestão. Universidade Politécnica de Hong Kong, Hong Kong, 2001.

MARTENS, C. D. P.; FREITAS, H.; BOISSIN, J. P. Orientação Empreendedora: Revisitando Conceitos e Aproximando com a Internacionalização das Organizações. Revista da Micro e Pequena Empresa, v. 4, n. 1, 2010.

MCCLELLAND, D. C. Characteristics of successful entrepreneurs. Journal of Creative Behavior, v. 21, n. 3, p. $219-233,1987$.

MCCLELLAND, D. C. A Sociedade Competitiva: realização e progresso social. Rio de Janeiro: Expressão e Cultura, 1972.

MINUZZI, J.; SANTOS, P. C. F.; LEZANA, A. G.; FILHO, N. C. Intenção Empreendedora em Alunos de Engenharia de Produção: Uma Análise com o Uso de Regressão Logística. In: ENCONTRO NACIONAL DE ENGENHARIA DE PRODUÇÃO, 2007, Foz do Iguaçu. Anais... Foz do Iguaçu: ABEPRO, 2007.

MITTON, D. G. The complete entrepreneur. Entrepreneurship Theory and Practice, v. 13, n. 3, p. $9-19,1989$.

MORALES-GUALDRÓN, S. T.; GUITIÉRREZ-GRACIS, A.; ROIG-DOBÓN, S. The entrepreneurial motivation in academia: a multimensional construct. Instituto de Gestión de la Innovación y del Conocimiento- IGENIO, 2008, Valencia. Working Paper n.11, 2008. 
NABI, G.; HOLDEN, R. Graduate entrepreneurship: intentions, education and training. Education + Training, v. 50, n. 7, p. $545-551,2008$.

PETROF, J. V. Entrepreneurial profile: A discriminant analysis. Journal of Small Business Management, v. 18, n. 4, 1980.

PINCHOT III, G. Intrapreneuring: por que você não precisa deixar a empresa para tornar-se um empreendedor. Tradução Nivaldo Montingelli Júnior. São Paulo: Harbra, 1989.

REYNOLDS, P. D. Sociology and entrepreneurship: Concepts and contributions. Entrepreneurship Theory \& Practice, v. 16, n.2, p. 47 - 70, 1991.

REYNOLDS, P. D. Who starts new firms? Linear additive versus interaction based models. Babson - Kauffman Entrepreneurship Research Conference, April 19 - 23, London Business School, England, 1995.

ROXAS, B. G.; CAYOCA-PANIZALES, R.; MAE DE JESUS, R. Entrepreneurial Knowledge and its Effects on Entrepreneurial Intentions: Development of a Conceptual Framework. Asia-Pacific Social Science Review, v. 8, n. 2, p. 61 - 77, 2008.

RUBIO LÓPEZ, E. A.; CORDÓN POZO, E.; AGOTE MARTÍN, A. L. Actitudes hacia la creación de empresas: un modelo explicativo. Revista Europea de Dirección y Economía de la Empresa, v. 8, n. 3, p. 37 - 52, 1999.

SALTMARSH, J. Education for Critical Citzenship: John Dewey's Contribution to the Pedagogy of Community Service Learning. Michigan Journal of Community Service Learning, v. 3, n. 1, p. 13 - 21, 1996.

SCOTT, M. G.; D. F. TWOMEY. The long-term supply of entrepreneurs: students career aspirations in relation to entrepreneurship. Journal of Small Business Management, v. 26, n. 4, p. $5-13,1988$.

SHANE. S. Academic Entrepreneurship: University spin-offs and wealth creation. Cheltenham: Edward Elgar Publishing, 2004.

SHAPERO, A.; SOKOL, L. The Social dimensions of entrepreneurship. Encyclopedia of Entrepreneurship, Englewood Cliffs, NJ: Prentice-Hall Inc. 1982, p. 72 - 90 . 
SHAPERO, A. An action programme for entrepreneurship. Multi-disciplinary Research Inc. Austin, Texas, 1971.

SMITHIKRAI, C. Entrepreneurial Potential of Thai University Students. Journal of Social Sciences and Humanities, v. 11, n. 3, p. $255-274,2005$.

SNELL, R.; LAU, A. Exploring local competencies salient for expanding small business. Journal Management Development, v. 13, n. 4, p. 4 - 15, 1994.

SOUZA, E. C. L. de. A disseminação da cultura empreendedora e a mudança na relação universidade - empresa. In.: Empreendedorismo: competência essencial para pequenas e médias empresas. Brasília: ANPROTEC, 2001.

STANWORTH, J. et al.. Who becomes an entrepreneur? International Small Business Journal, v. 8, n. 1, p. $11-22,1989$.

UNITED NATIONS UNIVERSITY. Institute of Advanced Studies. Education for sustainable development. 2005.2 Disponível em: <http://www.ias.unu.edu/research/esd.cf>. Acesso em: 10 jun. 2010.

VECIANA, J. M. El plan de empresa. Alta Dirección. p. 137. 1989.

ZAIN, Z. M.; AKRAM, A. M.; GHANI, E.K. L'esprit d'entreprise chez les etudiants en commerce malaisiens. Canadian Social Science. v. 6, n. 3, p. $34-44,2010$.

ZENG, F.; BU, X.; SU, L. Study on entrepreneurial process model for SIFE student team base don Timmons model. Journal of Chinese Entrepreneurship. v. 3, n. 3, p. $204-214,2011$. 